\title{
Polymorphisms in the Hsp70 gene locus are genetically associated with systemic lupus erythematosus
}

\author{
Barbara G Fürnrohr, ${ }^{1,2}$ Sven Wach, ${ }^{3}$ Jennifer A Kelly, ${ }^{4}$ Martin Haslbeck, ${ }^{5}$ Christian K \\ Weber, ${ }^{1}$ Christian M Stach, ${ }^{2}$ Axel J Hueber, ${ }^{6}$ Daniela Graef, ${ }^{1,2}$ Bernd M Spriewald, ${ }^{7}$ Karin \\ Manger, ${ }^{8}$ Martin Herrmann, ${ }^{2}$ Kenneth M Kaufman, ${ }^{4}$ Summer G Frank, ${ }^{4}$ Ellen Goodmon, ${ }^{4}$ \\ Judith A James, ${ }^{4}$ Georg Schett, ${ }^{2}$ Thomas H Winkler, ${ }^{3}$ John B Harley, ${ }^{4}$ Reinhard E Voll ${ }^{1,2}$
}

- Additional data are published online only. To view these files please visit the journal online (http://ard.bmj.com).

${ }^{1}$ IZKF Research Group 2, Nikolaus-Fiebiger Centre of Molecular Medicine, University of Erlangen-Nuremberg, Erlangen, Germany 2Department of Internal Medicine 3, University of Erlangen-Nuremberg, Erlangen, Germany

${ }^{3}$ Department of Genetics,

Nikolaus-Fiebiger Centre of Molecular Medicine, University of Erlangen-Nuremberg, Erlangen, Germany

${ }^{4}$ Oklahoma Medical Research Foundation, Oklahoma City, Oklahoma, USA

${ }^{5}$ Department of Chemistry, Technical University of Munich, Munich, Germany

${ }^{6}$ Division of Immunology, Infection and Inflammation, University of Glasgow, Glasgow, UK

${ }^{7}$ Department of Internal Medicine 5, University of Erlangen-Nuremberg, Erlangen, Germany

${ }^{8}$ Rheumatology Practice, Bamberg, Germany

\section{Correspondence to \\ Reinhard E Voll, IZKF Research Group 2, Nikolaus-Fiebiger Centre of Molecular Medicine and Department of Internal Medicine 3, University of Erlangen-Nuremberg, Glückstr 6, 91054 Erlangen, Germany: rvoll@molmed.uni-erlangen.de}

Accepted 4 April 2010

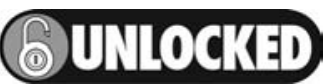

This paper is freely available online under the BMJ Journals unlocked scheme, see http:// ard.bmj.com/info/unlocked.dtl

\section{ABSTRACT}

Background Heat shock proteins (Hsps) play a role in the delivery and presentation of antigenic peptides and are thought to be involved in the pathogenesis of multifactorial diseases.

Objective To investigate genes encoding cytosolic Hsp70 proteins for associations of allelic variants with systemic lupus erythematosus (SLE).

Methods Case-control studies of two independent Caucasian SLE cohorts were performed. In a haplotypetagging single-nucleotide polymorphism approach, common variants of $H s p A 1 L, H s p A 1 A$ and $H s p A 1 B$ were genotyped and principal component analyses were performed for the cohort from the Oklahoma Medical Research Foundation (OMRF). Relative quantification of mRNA was carried out for each Hsp70 gene in healthy controls. Conditional regression analysis was performed to determine if allelic variants in $\mathrm{Hsp} 70$ act independently of HLA-DR3.

Results On analysis of common genetic variants of HspA1L, HspA1A and HspA1B, a haplotype significantly associated with SLE in the Erlangen-SLE cohort was identified, which was confirmed in the OMRF cohort. Depending on the cohorts, OR ranging from 1.43 to 1.88 and 2.64 to 3.16 was observed for individuals heterozygous and homozygous for the associated haplotype, respectively. Patients carrying the risk haplotype or the risk allele more often displayed autoantibodies to Ro and La in both cohorts. In healthy controls bearing this haplotype, the amount of HspA1A mRNA was significantly increased, whereas total Hsp70 protein concentration was not altered.

Conclusions Allelic variants of the Hsp70 genes are significantly associated with SLE in Caucasians, independently of HLA-DR3, and correlate with the presence of autoantibodies to Ro and La. Hence, the Hsp70 gene locus appears to be involved in SLE pathogenesis.

Heat shock proteins (Hsps) have been discovered as a result of their inducible expression in response to endogenous and exogenous stimuli such as elevated temperature, osmotic shock and the presence of cytotoxic agents. ${ }^{1}$ Functionally, most Hsps act as molecular chaperones by selectively recognising and binding non-native proteins, thereby preventing irreversible aggregation under physiological and stress conditions. ${ }^{2}$ By virtue of their peptide binding ability, this protein family modulates antigen processing and presentation and also contributes to immune responses against pathogens. ${ }^{3-5}$ Hsps are fundamental regulatory elements of cellular networks as they interact with a large number of proteins such as kinases, transcription factors and several other proteins influencing key steps in protein homoeostasis, cell growth, division, apoptosis and development. ${ }^{6}$ It has been shown that mutations and polymorphisms in chaperones, particularly Hsp70, are associated with several human, mostly immunemediated, diseases such as multiple sclerosis, ${ }^{8}$ Crohn's disease, ${ }^{9}$ Alzheimer's disease, ${ }^{10}$ Grave's disease, ${ }^{11}$ insulin-dependent diabetes mellitus ${ }^{12}$ and systemic lupus erythematosus (SLE). ${ }^{13} 14$ The chronic inflammatory autoimmune disease SLE involves multiple organs, including skin, joints, kidneys, brains, the cardiovascular system and serosal membranes. Immunologically, SLE is characterised by the presence of antinuclear autoantibodies, especially against double-stranded DNA and nucleosomes, activation of the complement system during flares, and type I interferon secretion. ${ }^{15} 16$ The aetiology of SLE remains elusive, but an interplay of genetic and environmental factors is considered to ultimately cause immune dysregulation, resulting in clinical symptoms. Many genetic variants on different chromosomes together with more than 31 different candidate genes have been reported and were confirmed as susceptibility loci for SLE by replication studies. ${ }^{17-20}$ A well-known susceptibility locus for SLE is the major histocompatibility complex (MHC) region on chromosome $6 \mathrm{p} 21$, which is linked to multiple autoimmune diseases. ${ }^{21}$ Mainly alleles of the MHC class II region such as human leucocyte antigen (HLA)-DR2 and HLA-DR3 were found to be associated with SLE, especially in Caucasians ${ }^{22} 23$; however, the exact mechanism by which these HLA molecules contribute to the immunopathogenesis is unknown. Owing to the extent of local linkage disequilibrium (LD), it is not yet clear whether the susceptibility to the disease is directly and exclusively associated with the products of specific MHC alleles or of a combination of certain MHC alleles with alleles of other linked genes, or just with certain polymorphisms of linked genes. Therefore, other genes mapping to the MHC loci have been considered to be additional candidates for disease susceptibility such as complement C2 and C4, tumour necrosis 
factor $\alpha,{ }^{24} 21$-hydroxylase and the superkiller viralicidic activity 2-like (Saccharomyces cerevisiae) gene (SKIVL2). ${ }^{25}$ In humans, three members of the Hsp70 gene family, referred to as Hsp70-1 (HspA1A), Hsp70-2 (HspA1B) and Hsp70-Hom (HspA1L), have been mapped to this $\mathrm{MHC}$ class III locus. ${ }^{26}$ Proteins of the Hsp70 family are commonly among the most highly conserved proteins known. Subtle genetic variations can result in diversified thermotolerance between species ${ }^{27}$ and may also be important determinants for the specific propagation of diseases such as SLE.

In this study, we examined a potential genetic association of the Hsp70 locus on chromosome 6p21.33a with SLE. In two independent Caucasian case-control studies, we found one haplotype to be significantly associated with SLE.

\section{PATIENTS AND METHODS \\ Study population and clinical evaluation}

A cohort of 212 unrelated well-documented German patients with SLE (184 women, 28 men) from the Department of Internal Medicine 3, University of Erlangen-Nuremberg, were randomly selected irrespective of stage or severity of the disease. All patients fulfilled the criteria of the American College of Rheumatology for the diagnosis of SLE. ${ }^{15} 16$ A median of 13 visits was recorded for each patient, varying from 1 to 54, and the follow-up period extended from 1985 to 2006. Autoantibodies against double-stranded DNA were present in $99 \%$ of our SLE cohort, at least at some time during the course of the disease. All abnormalities associated with SLE were recorded from the first visit either in Erlangen or from a well-documented history and at each follow-up visit. A group of 223 healthy unrelated donors volunteered as controls. The study was approved by the ethics committee of the University of Erlangen-Nuremberg, and written informed consent was obtained from all participants.

A second cohort consisting of 934 unrelated American patients with SLE and normal healthy donors of European descent from the Lupus Family Registry and Repository (http://lupus.omrf. org) was kindly provided by the Oklahoma Medical Research Foundation (OMRF). Data on autoantibody titres were derived from both medical records and Clinical Laboratory Improvement Act-approved laboratory data.

\section{Genotyping methods}

Genomic DNA was isolated from $0.5 \mathrm{ml}$ peripheral blood using standard procedures. Identification of haplotypes was performed with the Haploview 3.2 CI method based on the HapMap Data release 21 (http://www.hapmap.org/). Five different tagging single-nucleotide polymorphisms (SNPs) (rs2075800, rs2227956, rs1043618, rs2763979, rs3115673) were selected on the basis of LD to discriminate the major haplotypes of the Hsp70 gene locus that are present with a frequency above $1 \%$ in the Centre d'Etude du Polymorphisme Humaine (CEPH) population. Genotyping was carried out in an iCycler real-time PCR setup (Bio-Rad, Munich, Germany) using TaqMan SNP Genotyping Assays and TaqMan Universal PCR Master Mix, No AmpErase UNG (Applied Biosystems, Darmstadt, Germany).

\section{Blood samples}

Venous blood was collected from healthy donors and patients with SLE in $20 \mathrm{ml}$ heparin-containing tubes for isolation of cells, or without anticoagulant for serum (Monovette; Sarstedt, Nuembrecht, Germany). Serum samples were centrifuged at $2000 \mathrm{~g}$ for $30 \mathrm{~min}$ at $4^{\circ} \mathrm{C}$ and stored at $-20^{\circ} \mathrm{C}$.

\section{Cell culture}

The human cell line HEK293T (CRL-11268; ATCC, Wesel, Germany) and peripheral blood mononuclear cells (PBMCs) were grown in Dulbecco's modified Eagle medium containing $10 \%$ fetal bovine serum, $2 \mathrm{mM}$ L-glutamine, $100 \mathrm{U} / \mathrm{ml}$ penicillin, $100 \mu \mathrm{g} / \mathrm{ml}$ streptomycin (all from Invitrogen Life Technologies, Karlsruhe, Germany) at $5 \% \mathrm{CO}_{2}$ and $37^{\circ} \mathrm{C}$. PBMCs were isolated as described previously. ${ }^{28}$ Heat shock treatment was carried out for $2 \mathrm{~h}$ at $42^{\circ} \mathrm{C}$ followed by a recovery period $\left(37^{\circ} \mathrm{C}\right)$ either for $3 \mathrm{~h}$ for subsequent RNA isolation or overnight for western blotting.

\section{Sodium dodecyl sulfate-polyacrylamide gel electrophoresis (SDS-PAGE) and western blotting}

Isolated PBMCs lysed in $50 \mu \mathrm{l}$ SDS-PAGE sample buffer were subjected to SDS-PAGE as described.$^{29}$ Proteins were transferred on to a nitrocellulose membrane (Millipore, Bedford, UK) using semidry apparatus (Serva, Heidelberg, Germany) according to the manufacturer's recommendations. After blocking $(5 \%(\mathrm{w} / \mathrm{v})$ milk powder, $10 \mathrm{mM}$ Tris/HCl, $100 \mathrm{mM} \mathrm{NaCl}, 0.05 \%$ (v/v) Tween-20, pH 7.4), primary antibodies against Hsp72 (1:30 000) (SPA-812; Biomol, Hamburg, Germany) and $\beta$-actin (1:1000) (Sigma-Aldrich, Hamburg, Germany) were applied. After washing, blots were incubated with secondary IRDye 800CW goat anti-rabbit antibody (1:10 000) (LI-COR Bioscience, Bad Homburg, Germany). Integrated intensity of the bands was quantified using the Odyssey infrared imaging system (LI-COR Bioscience).

\section{RNA isolation and quantitative PCR}

Total RNA was extracted from $2 \times 10^{6} \mathrm{PBMC}$ using the RNeasy kit (Qiagen, Hilden, Germany). cDNA was prepared with Moloneymurineleukaemia virus reverse transcriptase (Promega, Mannheim, Germany) and oligo(dT $)_{20}$ primers according to the manufacturer's instructions. Quantification of cDNA was carried out using ABsolute QPCR SYBR Green ROX Mix (Thermo Fisher Scientific, Schwerte, Germany) in a StepOnePlus Real-Time PCR System (Applied Biosystems) with the following primers: HspA1A, 5'-GCTGCTGCGACAGTCCACTAC-3' and $55^{\prime}-$ C C C T G C T C T C T GTCGGCTC G GC-3'; HspA1B, 5' - A G CTGCTGCGAGGGTCCGCTTC-3' and 5'- GTGC C C T G C T C T G T G G GCT C C - 3'; HspA1L, 5'-ACAGGGTATGTGCCTGGAAG-3' and 5'-GGTGGTGCATGAGACTCCTT-3'; GAPDH, $5^{\prime}$ - CATGAGAA GTATGACAACAGCCT-3' and 5'-AGTCCTTCCACGATACCAAAGT-3'. Relative quantification of cDNA was based on the comparative $C_{t}$ method using glyceraldehyde-3-phosphate dehydrogenase (GAPDH) as endogenous control. $\Delta C_{t}$ levels were calculated in triplicate for four different donors of each genotype and normalised to one randomly selected donor homozygous for cytosine.

\section{Stratification analysis}

Principal component analysis (PCA) was performed using Eigensoft ${ }^{30}$ on 905 of the 934 Oklahoma samples using casecontrol data from 17875 SNPs collected from a separate candidate gene study. After removal of genetic outliers (12 cases and 7 controls), 493 cases and 393 controls remained for analysis. We then performed genomic control analysis to calculate the inflation factor $(\lambda)$, which produced a value of 1.21 for these samples (the value for the pretrimmed sample was 1.24). After trimming of the sample, we performed a logistic regression analysis using the PCA values as covariates, using PLINK $^{31}$ to remove 
the final source of confounding via admixture, which produced a corrected $\mathrm{p}=0.0145(\mathrm{OR}=1.292)$ at $\mathrm{rs} 2763979$ and $\mathrm{p}=0.4762$ $(\mathrm{OR}=0.903)$ at $\mathrm{rs} 3115673$ in these samples.

\section{Conditional regression analysis}

For the OMRF samples, a surrogate SNP (rs3129860) was chosen from the OMRF Lupus Large Association Study 1 (LLAS1) data that is in strong $\mathrm{LD}\left(\mathrm{r}^{2}=0.95\right)$ with the HLA-DRB1 tagging SNP (rs701831). Conditional regression analysis was performed with the surrogate SNP and SNP Hsp70-4 on the OMRF samples using PLINK ${ }^{31}$.

\section{Statistical analysis}

Statistical analysis for the case-control study was carried out with the Haploview V3.32 software package. ${ }^{32}$ Haplotype-based association testing was carried out using PLINK. ${ }^{31}$ The Fisher exact test and Mann-Whitney $U$ test were performed with Prism 4 software. p Values $<0.05$ were considered significant.

\section{RESULTS}

\section{Genetic association of Hsp70 haplotypes with SLE}

To investigate a possible contribution of Hsp70 polymorphisms to SLE susceptibility, we performed a case-control association study followed by an independent replication study. As shown in figure 1A, the three intronless Hsp70 genes, HspA1L, HspA1A and $H s p A 1 B$, are located on chromosome 6p21.33a. On the basis of information on the CEPH population provided by the HapMap database, we selected five haplotype-tagging SNPs to define haplotypes with more than $1 \%$ frequency (figure 1B) and with high
LD depicted in the LD plot (figure 1C). All observed SNP allele frequencies were concordant with those reported in the NCBI dbSNP database, and the genotype frequencies were in Hardy-Weinberg equilibrium. In the Erlangen cohort, polymorphism Hsp70-4 was identified to be significantly associated with SLE ( $p=0.016)$. The major allele of this SNP, cytosine, was present in $61 \%$ of patients with SLE compared with $69 \%$ in controls, suggesting either cytosine as a protective allele or thymine as part of a risk allele for SLE. Two reconstructed haplotypes were also strongly associated with SLE, with C-A-C-T-G being more frequently $(\mathrm{p}=0.0022)$ present in patients with SLE $(26 \%)$ than in controls $(17 \%)$. Conversely, the haplotype $\mathrm{C}-\mathrm{A}-\mathrm{C}-\mathrm{C}-\mathrm{G}(\mathrm{p}=0.0444)$ was found more frequently in healthy individuals (table 1). In addition, we analysed whether haplotypes have independent or interactive effects. By testing each haplotype against all others, we found that only the risk-conferring $(p=0.0018)$ and protective $(p=0.045)$ haplotypes are significant in the haplotype-specific test. Even when all haplotype effects were tested together in an interaction model, only this combined haplotype was found to be significant.

Genotyping of the second cohort, OMRF, was performed only for SNPs Hsp70-4 and Hsp70-5, because the two significantly associated haplotypes $\mathrm{C}-\mathrm{A}-\mathrm{C}-\mathrm{T}-\mathrm{G}$ and $\mathrm{C}-\mathrm{A}-\mathrm{C}-\mathrm{C}-\mathrm{G}$ can be identified by these SNPs. In this independent replication cohort, the genetic associations of both SNP Hsp70-4 and the representative haplotypes $\mathrm{T}-\mathrm{G}$ and $\mathrm{C}-\mathrm{G}$, respectively, were confirmed with even higher significance (table 2). Combined analysis of both cohorts reached a $\mathrm{p}$ value of $3.64 \times 10^{-7}$ for the haplotype T-G and 0.0002 for SNP Hsp70-4.

To determine the effect size of SNP Hsp70-4 and the Hsp70 haplotypes for SLE, ORs were calculated using unstratified

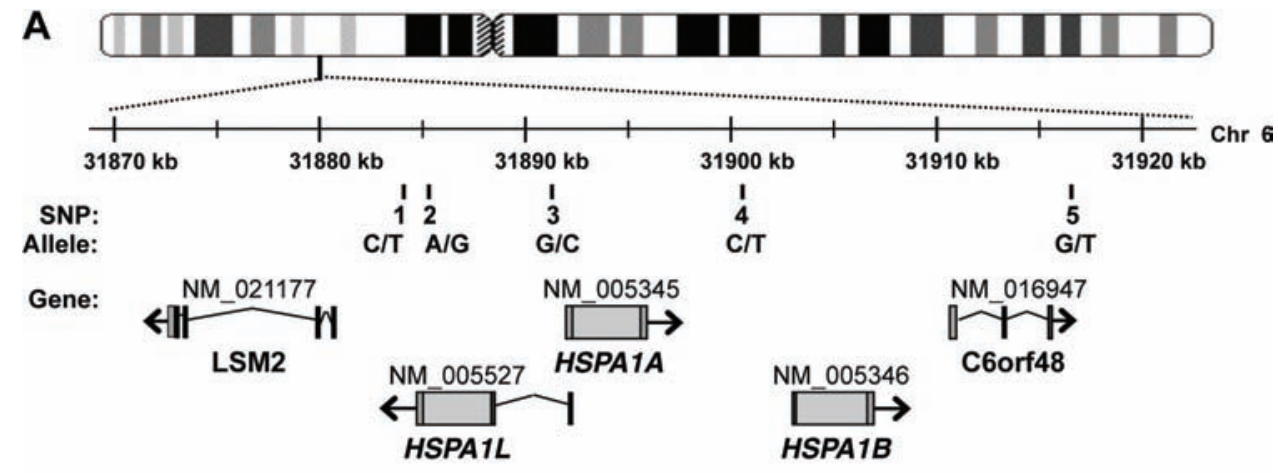

B

\begin{tabular}{|cccccc|}
\hline \multicolumn{4}{|c|}{ Reconstructed Hsp70 haplotypes: } \\
\hline $\mathbf{1}$ & $\mathbf{2}$ & $\mathbf{3}$ & $\mathbf{4}$ & $\mathbf{5}$ & Frequency (\%) \\
$\boldsymbol{\nabla}$ & $\boldsymbol{\nabla}$ & $\boldsymbol{\nabla}$ & $\boldsymbol{\nabla}$ & $\boldsymbol{\nabla}$ & 29.2 \\
C & G & G & C & G & 27.5 \\
T & A & G & C & G & 16.7 \\
C & A & C & T & G & 11.7 \\
C & A & C & T & T & 5.8 \\
C & A & C & C & G & 5.0 \\
C & A & G & C & G & 4.2 \\
C & A & G & T & T & \\
\hline
\end{tabular}

C

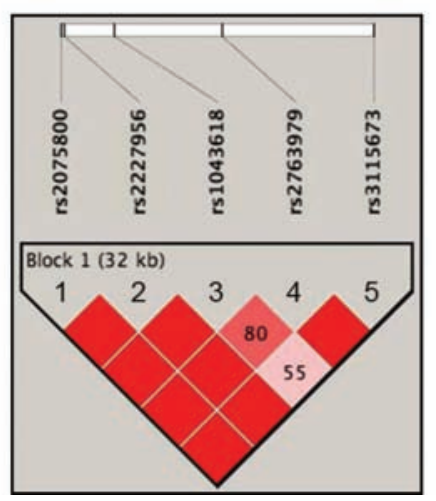

Figure 1 Overview and linkage disequilibrium (LD) of the human genomic locus containing three Hsp70 genes on chromosome 6. (A) The human susceptibility locus for systemic lupus erythematosus on chromosome $6 \mathrm{p} 21.33$ covers a cluster of three Hsp70 genes: HspA1L, HspA1A and HspA1B. (B) On the basis of LD, five haplotype-tagging single-nucleotide polymorphisms (SNPs) were selected to identify the major haplotypes (>1\% frequency). (C) LD prime charts generated using Haploview V3.32 software summarise LD patterns in Caucasians (Centre d'Etude du Polymorphisme Humaine). Dark red boxes represent regions of high pairwise $r^{2}$, whereas bright red boxes show lower pairwise $r^{2}$. The numbers in the boxes depict pairwise $r^{2}$ values, with empty cells representing pairwise $r^{2}=1$. 
Table 1 Genetic association of Hsp70 haplotypes with SLE in the Erlangen cohort

\begin{tabular}{|c|c|c|c|c|c|}
\hline \multirow[b]{2}{*}{ SNP No } & \multirow[b]{2}{*}{ rs No } & \multirow[b]{2}{*}{ Major/minor allele } & \multicolumn{2}{|c|}{ Frequency of major allele (\%) } & \multirow{2}{*}{$\begin{array}{l}\text { Single marker association } \\
\text { ( } \mathrm{p} \text { value) }\end{array}$} \\
\hline & & & SLE $(n=212)$ & Controls $(n=223)$ & \\
\hline Hsp70-1 & rs2075800 & $\mathrm{C} / \mathrm{T}$ & 68.0 & 65.7 & 0.4792 \\
\hline Hsp70-2 & rs2227956 & $A / G$ & 81.4 & 83.0 & 0.5483 \\
\hline Hsp70-3 & rs1043618 & $\mathrm{G} / \mathrm{C}$ & 60.2 & 65.3 & 0.1306 \\
\hline Hsp70-4 & rs2763979 & $\mathrm{C} / \mathrm{T}$ & 61.0 & 68.8 & 0.0160 \\
\hline \multirow[t]{2}{*}{ Hsp70-5 } & rs3115673 & $\mathrm{G} / \mathrm{T}$ & 88.3 & 87.4 & 0.6902 \\
\hline & & & \multicolumn{2}{|c|}{ Frequency of haplotype (\%) } & Haplotype association \\
\hline Haplotype & & Overall frequency & SLE $(n=212)$ & Controls $(n=223)$ & ( $p$ value) \\
\hline $\mathrm{T}-\mathrm{A}-\mathrm{G}-\mathrm{C}-\mathrm{G}$ & & 32.7 & 32.1 & 33.3 & 0.7034 \\
\hline $\mathrm{C}-\mathrm{A}-\mathrm{C}-\mathrm{T}-\mathrm{G}$ & & 21.4 & 25.8 & 17.2 & 0.0022 \\
\hline C-G-G-C-G & & 16.5 & 16.2 & 16.8 & 0.7999 \\
\hline $\mathrm{C}-\mathrm{A}-\mathrm{C}-\mathrm{T}-\mathrm{T}$ & & 9.2 & 9.0 & 9.5 & 0.8023 \\
\hline $\mathrm{C}-\mathrm{A}-\mathrm{G}-\mathrm{C}-\mathrm{G}$ & & 8.3 & 6.9 & 9.7 & 0.1455 \\
\hline $\mathrm{C}-\mathrm{A}-\mathrm{C}-\mathrm{C}-\mathrm{G}$ & & 6.4 & 4.7 & 8.1 & 0.0444 \\
\hline C-A-G-T-T & & 2.9 & 2.6 & 3.1 & 0.6311 \\
\hline
\end{tabular}

SLE, systemic lupus erythematosus; SNP, single-nucleotide polymorphism.

Table 2 Replication study of the genetic association of Hsp70 haplotypes with SLE in the OMRF cohort

\begin{tabular}{|c|c|c|c|c|c|}
\hline \multirow[b]{2}{*}{ SNP No } & \multirow[b]{2}{*}{ rs No } & \multirow[b]{2}{*}{ Major/minor allele } & \multicolumn{2}{|c|}{ Frequency of major allele (\%) } & \multirow{2}{*}{$\begin{array}{l}\text { Single marker association } \\
\text { ( } \mathrm{p} \text { value) }\end{array}$} \\
\hline & & & SLE $(n=519)$ & Controls $(n=415)$ & \\
\hline Hsp70-4 & rs2763979 & $\mathrm{C} / \mathrm{T}$ & 59.3 & 65.5 & 0.0071 \\
\hline \multirow[t]{2}{*}{ Hsp70-5 } & rs3115673 & $\mathrm{G} / \mathrm{T}$ & 87.7 & 86.5 & 0.4614 \\
\hline & & & \multicolumn{2}{|c|}{ Frequency of haplotypes (\%) } & Haplotype association \\
\hline Haplotype & & Overall frequency & SLE $(n=519)$ & Controls $(n=415)$ & (p value) \\
\hline $\mathrm{C}-\mathrm{G}$ & & 60.9 & 57.7 & 64.9 & 0.0018 \\
\hline $\mathrm{T}-\mathrm{G}$ & & 26.2 & 29.8 & 21.7 & 0.000074 \\
\hline T-T & & 11.7 & 10.8 & 12.8 & 0.1963 \\
\hline $\mathrm{C}-\mathrm{T}$ & & 1.2 & 1.6 & 0.6 & 0.0665 \\
\hline
\end{tabular}

OMRF, Oklahoma Medical Research Foundation; SLE, systemic lupus erythematosus; SNP, single-nucleotide polymorphism.

Table 3 ORs for SNP Hsp70-4 and different Hsp70 haplotypes comparing patients with SLE with healthy controls

\begin{tabular}{|c|c|c|c|}
\hline Population: OR for SNP Hsp70-4 alleles & OR & p Value & $95 \% \mathrm{CI}$ \\
\hline \multicolumn{4}{|l|}{ Erlangen $(n=435)$} \\
\hline$C$ versus $T$ & 1.43 & 0.01 & 1.08 to 1.89 \\
\hline \multicolumn{4}{|l|}{ OMRF $(n=934)$} \\
\hline $\mathrm{C}$ versus $\mathrm{T}$ & 1.30 & 0.008 & 1.07 to 1.58 \\
\hline Population: OR for haplotypes & OR & p Value & $95 \% \mathrm{Cl}$ \\
\hline \multicolumn{4}{|l|}{ Erlangen $(n=435)$} \\
\hline $\mathrm{C}-\mathrm{G} / \mathrm{C}-\mathrm{G}$ versus $\mathrm{C}-\mathrm{G} / \mathrm{T}-\mathrm{G}$ & 1.88 & 0.009 & 1.18 to 3.02 \\
\hline $\mathrm{C}-\mathrm{G} / \mathrm{C}-\mathrm{G}$ versus $\mathrm{T}-\mathrm{G} / \mathrm{T}-\mathrm{G}$ & 2.64 & 0.06 & 1.02 to 6.85 \\
\hline \multicolumn{4}{|l|}{ OMRF $(n=934)$} \\
\hline $\mathrm{C}-\mathrm{G} / \mathrm{C}-\mathrm{G}$ versus $\mathrm{C}-\mathrm{G} / \mathrm{T}-\mathrm{G}$ & 1.43 & 0.03 & 1.04 to 1.96 \\
\hline $\mathrm{C}-\mathrm{G} / \mathrm{C}-\mathrm{G}$ versus $\mathrm{T}-\mathrm{G} / \mathrm{T}-\mathrm{G}$ & 3.16 & $<0.001$ & 1.67 to 5.97 \\
\hline
\end{tabular}

ORs were calculated using the Fisher exact test.

OMRF, Oklahoma Medical Research Foundation; SLE, systemic lupus erythematosus.

genotyping data. For our newly identified SNP, Hsp70-4, the OR for donors bearing a T allele is 1.43 (95\% CI 1.08 to 1.89$)$ and 1.3 (95\% CI 1.07 to 1.58$)$ for the Erlangen and OMRF cohort, respectively. When the analysis was performed for haplotypes, the OR for patients bearing one T-G haplotype compared with those homozygous for $\mathrm{C}-\mathrm{G}$ is 1.88 (95\% CI 1.18 to 3.02$)$ in the Erlangen cohort and 1.43 (95\% CI 1.04 to 1.96) in the OMRF cohort. When homozygous donors for $\mathrm{T}-\mathrm{G}$ and $\mathrm{C}-\mathrm{G}$ are compared, the OR is 2.64 (95\% CI 1.02 to 6.85) and 3.16 (95\% CI 1.67 to 5.97 ) in the Erlangen and OMRF cohort, respectively (table 3).

\section{Conditional regression analysis}

The distance between the three Hsp70 genes, located in the MHC class III region, and HLA-DRB1 (MHC class II) is $\sim 1 \mathrm{Mb}$. The LD plot for European-derived samples genotyped in the International HapMap Project (online supplementary figure 1) shows incomplete linkage in this region. However, owing to long-range linkage in this entire locus, we performed conditional regression analysis to investigate whether the genetic association of SNP Hsp70-4 is independent of HLA-DRB1. One surrogate SNP (rs2763979) that shows strong LD with SNP rs701831 in HLA-DRB1 was chosen 

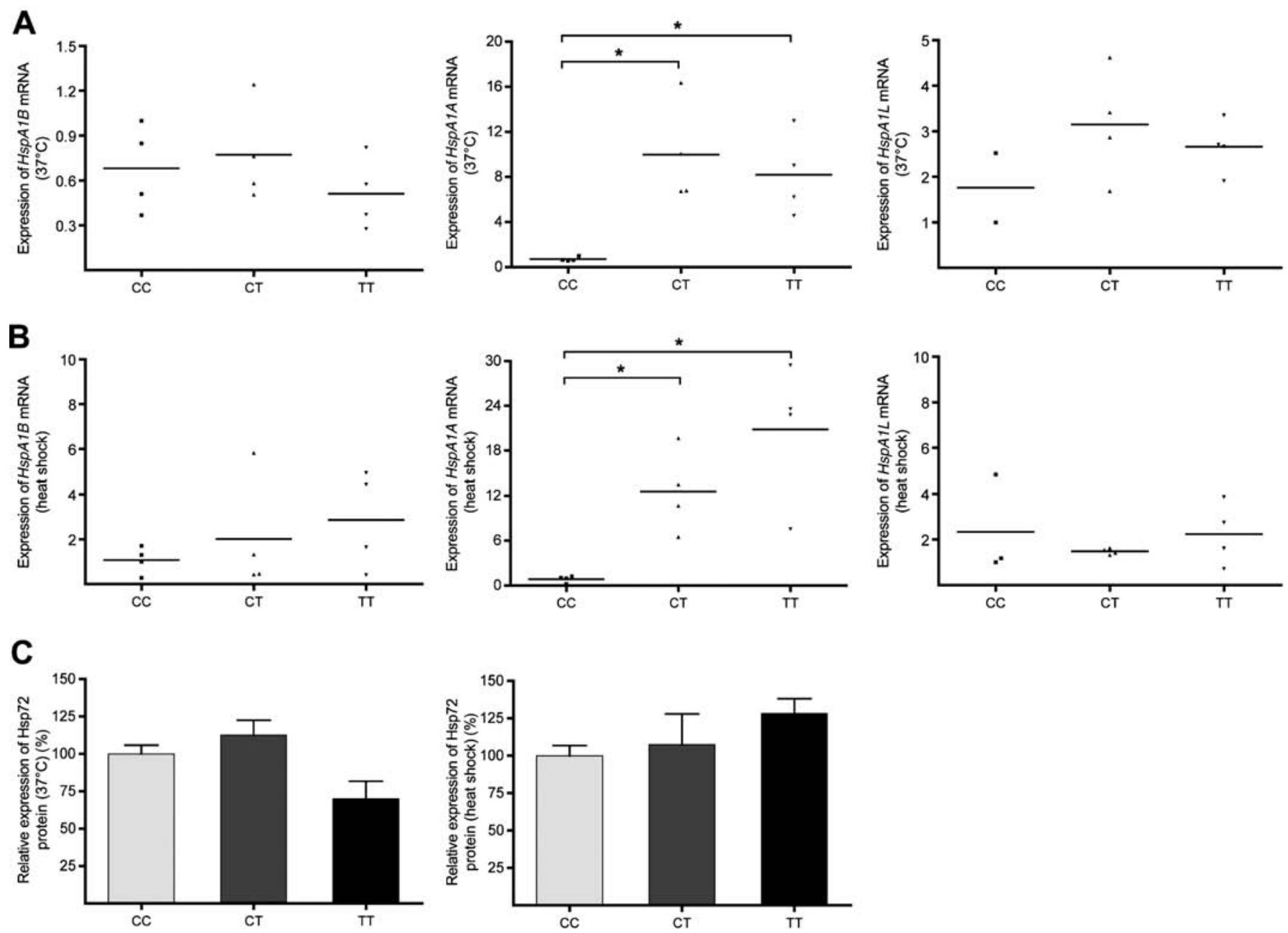

Figure 2 Influence of Hsp70 polymorphisms on Hsp70 mRNA and protein expression. Primary human peripheral blood mononuclear cells (PBMCs) from donors with defined genotypes were analysed for relative expression of $H s p A 1 L, H s p A 1 A$ and $H s p A 1 B$ mRNA under physiological conditions (A) or after heat shock (B). Data in (A) and (B) are expressed in arbitrary units that represent one out of three independent experiments. Statistical analyses were performed using the Mann-Whitney $U$ test. $p$ Values $<0.05$ were considered significant. (C) Primary human PBMCs with or without heat shock treatment were analysed for total Hsp72 protein expression. The integrated intensity of the bands for Hsp72 and $\beta$-actin were quantified. Data represent the mean result of three independent experiments.

from the OMRF LLAS1 genotyping data, as the HLA-DRB1 tagging SNP itself was not included in LLAS1 dataset. We found that SNP Hsp70-4 (rs2763929) acts independently of the HLA-DRB1 surrogate $(p=0.019)$ and vice versa $(p=0.045)$.

\section{Correlation of the haplotype T-G with clinical variables in patients with SLE}

To examine a potential effect of the risk haplotype $T-G$ on disease manifestation, we correlated clinical variables of the Erlangen cohort with the associated haplotypes in a cumulative analysis. Patients with haplotype T-G were significantly more frequently positive for anti-Ro and anti-La autoantibody responses, lupus anticoagulant and oronasal ulcers than those with haplotype $\mathrm{C}-\mathrm{G}$ (online supplementary figure $2 \mathrm{~A}$ ). In contrast, when SLE patients bearing HLA-DR3 alleles were compared with those lacking an HLA-DR3 allele (HLA-DRx/x), no statistically significant correlations with clinical or immunological disease variables could be detected (online supplementary figure $2 \mathrm{~B}$ ). These data also indicate that the Hsp70 haplotype T-G contributes independently of HLA-DR3 to the manifestation of SLE. As depicted in table 4, patients either heterozygous or homozygous for allele $\mathrm{T}$ or for the haplotype $\mathrm{T}-\mathrm{G}$ were more frequently positive for anti-Ro and anti-La autoantibodies in both SLE cohorts.

\section{Increased mRNA expression of HspA1A in PBMCs from healthy donors homozygous for thymine at SNP Hsp70-4}

SNP Hsp70-4 is located between the genes for HspA1A and $H \operatorname{sp} A 1 B$, thus allelic variations at this position may influence the expression of HspA1A and HspA1B. To prevent the influence of medication, we used PBMCs from 12 healthy donors who were either homozygous for thymine or cytosine or were heterozygous at SNP Hsp70-4. Figure 2A,B shows a significantly increased expression of HspA1A mRNA in healthy donors homozygous or heterozygous for thymine compared with homozygous carriers of cytosine, both under physiological conditions (figure 2A) and after heat stress (figure $2 \mathrm{~B}$ ). In contrast, we detected no significant differences in mRNA levels for either HspA1B or HspA1L under all conditions tested. In accordance with other reports, ${ }^{33} H s p A 1 A$ and $H \operatorname{sp} A 1 B$ were found to be strongly heat inducible, whereas HspA1L was weakly induced after heat stress (data not shown). To further investigate the expression of the three Hsp70 genes (HspA1L, HspA1A and HspA1B), the total amount of all three Hsp72 proteins was determined by western blot (figure $2 \mathrm{C}$ ), as 
Table 4 ORs for SLE patients with different Hsp70-4 genotypes and haplotypes (Hsp70-4 and -5 ) based on the presence of anti-Ro and anti-La autoantibodies

\begin{tabular}{|c|c|c|c|c|}
\hline $\begin{array}{l}\text { Population: Hsp70-4 } \\
\text { genotypes }\end{array}$ & $\begin{array}{l}\text { Autoantibodies } \\
\text { against }\end{array}$ & $\mathrm{p}$ Value & $\mathbf{O R}$ & $95 \% \mathrm{Cl}$ \\
\hline Erlangen & Ro & & & \\
\hline $\mathrm{C} / \mathrm{C}$ versus $\mathrm{T} / \mathrm{T}$ & & 0.02 & 2.74 & 1.15 to 6.52 \\
\hline \multirow[t]{2}{*}{$\mathrm{C} / \mathrm{C}$ versus $\mathrm{C} / \mathrm{T}$} & & 0.02 & 2.15 & 1.12 to 4.13 \\
\hline & La & & & \\
\hline $\mathrm{C} / \mathrm{C}$ versus $\mathrm{T} / \mathrm{T}$ & & 0.02 & 3.01 & 1.18 to 7.70 \\
\hline $\mathrm{C} / \mathrm{C}$ versus $\mathrm{C} / \mathrm{T}$ & & NS & 1.36 & 0.63 to 2.97 \\
\hline OMRF & Ro & & & \\
\hline $\mathrm{C} / \mathrm{C}$ versus $\mathrm{T} / \mathrm{T}$ & & NS & 1.27 & 0.68 to 2.37 \\
\hline \multirow[t]{2}{*}{$\mathrm{C} / \mathrm{C}$ versus $\mathrm{C} / \mathrm{T}$} & & 0.03 & 1.67 & 1.04 to 2.68 \\
\hline & La & & & \\
\hline $\mathrm{C} / \mathrm{C}$ versus $\mathrm{T} / \mathrm{T}$ & & 0.02 & 2.73 & 1.12 to 6.65 \\
\hline $\mathrm{C} / \mathrm{C}$ versus $\mathrm{C} / \mathrm{T}$ & & 0.001 & 3.24 & 1.53 to 6.88 \\
\hline $\begin{array}{l}\text { Population: haplotypes } \\
\text { (Hsp70-4 and Hsp-5) }\end{array}$ & $\begin{array}{l}\text { Autoantibodies } \\
\text { against }\end{array}$ & $\mathrm{p}$ Value & $\mathbf{O R}$ & $95 \% \mathrm{Cl}$ \\
\hline Erlangen & Ro & & & \\
\hline $\mathrm{C}-\mathrm{G} / \mathrm{C}-\mathrm{G}$ versus $\mathrm{T}-\mathrm{G} / \mathrm{T}-\mathrm{G}$ & & 0.004 & 5.14 & 1.57 to 16.84 \\
\hline \multirow[t]{2}{*}{$\mathrm{C}-\mathrm{G} / \mathrm{C}-\mathrm{G}$ versus $\mathrm{C}-\mathrm{G} / \mathrm{T}-\mathrm{G}$} & & 0.001 & 3.21 & 1.58 to 6.53 \\
\hline & La & & & \\
\hline $\mathrm{C}-\mathrm{G} / \mathrm{C}-\mathrm{G}$ versus $\mathrm{T}-\mathrm{G} / \mathrm{T}-\mathrm{G}$ & & 0.01 & 4.17 & 1.29 to 13.55 \\
\hline $\mathrm{C}-\mathrm{G} / \mathrm{C}-\mathrm{G}$ versus $\mathrm{C}-\mathrm{G} / \mathrm{T}-\mathrm{G}$ & & NS & 1.91 & 0.85 to 4.29 \\
\hline OMRF & Ro & & & \\
\hline $\mathrm{C}-\mathrm{G} / \mathrm{C}-\mathrm{G}$ versus $\mathrm{T}-\mathrm{G} / \mathrm{T}-\mathrm{G}$ & & NS & 1.65 & 0.78 to 3.50 \\
\hline \multirow[t]{2}{*}{$\mathrm{C}-\mathrm{G} / \mathrm{C}-\mathrm{G}$ versus $\mathrm{C}-\mathrm{G} / \mathrm{T}-\mathrm{G}$} & & NS & 1.65 & 0.97 to 2.69 \\
\hline & La & & & \\
\hline $\mathrm{C}-\mathrm{G} / \mathrm{C}-\mathrm{G}$ versus $\mathrm{T}-\mathrm{G} / \mathrm{T}-\mathrm{G}$ & & 0.05 & 2.72 & 0.97 to 7.66 \\
\hline $\mathrm{C}-\mathrm{G} / \mathrm{C}-\mathrm{G}$ versus $\mathrm{C}-\mathrm{G} / \mathrm{T}-\mathrm{G}$ & & 0.007 & 2.81 & 1.30 to 6.05 \\
\hline
\end{tabular}

ORs were calculated using $\chi^{2}$ test.

OMRF, Oklahoma Medical Research Foundation; SLE, systemic lupus erythematosus.

gene products are $99 \%$ identical and currently indistinguishable by available antibodies. The overall Hsp72 protein level was not altered in PBMCs from donors with thymine or cytosine at SNP Hsp70-4, when kept at $37^{\circ} \mathrm{C}$ or after heat shock. To examine a potential direct influence of genotypes of SNP Hsp70-4, located upstream of the HspA1B promoter, on the expression of $H s p A 1 B$, the promoter activity was analysed by reporter assays (online supplementary methods and supplementary figure 3 ). The promoter of $H s p A 1 B$ was highly inducible by heat stress and to a lower extent by osmotic shock. In agreement with mRNA quantification in PBMCs of healthy donors, similar luciferase activities for both promoter constructs were reproducibly observed for all conditions tested, arguing against a direct effect of SNP Hsp70-4 on the promoter activity of HspA1B.

\section{DISCUSSION}

In our study, we identified one haplotype (T-G) in the Hsp70 locus as a potential genetic risk factor for SLE using a haplotypetagging SNP approach and confirmed the genetic association in an independent case-control cohort. In a cumulative analysis, this haplotype correlated in SLE patients with the presence of clinical variables such as autoantibodies to Ro and $\mathrm{La}$, as well as lupus anticoagulant. To our knowledge this is the first genetic association study on autoimmune diseases such as SLE that takes into account the entire Hsp70 locus on 6p21.33 with respect to the underlying LD. Previous studies aimed to identify individual SNPs, such as the $8.5 \mathrm{~kb}$ PstI polymorphism at position 1267 within the HspA1B coding region representing a silent mutation. This SNP has been found to be associated with SLE in African-Americans and in a Spanish, but not a Mexican Mestizo, population. ${ }^{13} 1434$
Polymorphisms in HspA1L (2437, coding), HspA1A (-110, 5' flanking; and 190, 5' untranslated region) and $\operatorname{Hsp} A 1 B$ (1267, coding) have been discovered to correlate with increased longevity in Danish populations. ${ }^{35} 36$ Most Hsps can positively influence cellular maintenance and repair mechanisms through their chaperone activity. ${ }^{37-39}$ Therefore Hsps are generally recognised as protective elements increasingly gaining attention in relation to diseases and immunological processes. ${ }^{6}$ Associations of polymorphisms within the three Hsp70 genes with Ménière's disease, ${ }^{40}$ noise-induced hearing loss,$^{41}$ high-altitude pulmonary oedema ${ }^{42}$ and coronary heart disease ${ }^{43}$ have recently been discovered. In these reports, major importance was determined for two SNPs in HspA1A that are located at positions -110 (rs1008438) and +190 (rs1043618), the latter also being part of our study (Hsp70-3). As we found a genetic association for the haplotypes T-G and $\mathrm{C}-\mathrm{G}$ (Hsp70-4 and Hsp70-5) with SLE, we stratified the samples according to SNP Hsp70-4 for functional analyses and discovered differences in mRNA regulation for $H s p A 1 A$ (figure $2 \mathrm{~A}, \mathrm{~B}$ ). In spite of divergent mRNA concentrations for HspA1A, the protein expression level of all three Hsp70 genes was not altered in PBMCs from different donors either under steady-state conditions or after heat shock (figure 2C), which might be a result of negative transcriptional feedback regulation. Whether increased transcription of HspA1A mRNA is functionally relevant for the pathogenesis of SLE remains to be elucidated. Because of the extent of $\mathrm{LD}$, we are currently unable to rule out indirect effects that might arise from potentially causal variants of Hsp70-3 or other unknown factors. As we have analysed the expression of Hsp70 genes in PBMCs, a tissuespecific expression of $\mathrm{Hsp} 70$ is possible and may be relevant for SLE. Because of long-range linkage in the lupus-associated DR3 'autoimmune' extended haplotype, we performed conditional regression analysis to investigate if the associated SNP Hsp70-4 acts independently of HLA-DR3. Tracking HLA-DR3 using a surrogate SNP, we found SNP Hsp70-4 to be independent, and vice versa. These results are in accordance with recent investigations carried out by high-density screening of the MHC genes, producing strong evidence for independent susceptibility regions in the MHC locus. ${ }^{44}$ In addition, we showed that the Hsp70 haplotype T-G, as well as the SNP Hsp70-4, correlated in both cohorts with the presence of autoantibodies to Ro and La in patients with SLE.

In summary, our data indicate an important role for Hsp70 molecules in the aetiology and pathogenesis of SLE, consistent with the involvement of Hsp70 molecules in antigen delivery and presentation as well as protein folding and homoeostasis.

Acknowledgements We thank Gerhard Groer for critical reading of the manuscript, Rüdiger Müller for help with statistical analyses, and Birgit Lauer for HLA genotyping. Portions of the samples used in this study were obtained from the Lupus Family Registry and Repository (AR62277) (see http://lupus.omrf.org).

Funding This study was supported by the Interdisciplinary Center of Clinical Research (IZKF) of the University Hospital Erlangen, project N2. This work has been supported by the National Institutes of Health (grants Al24717, AR62277, AR42460, AR49084, RR20143, AR053483, N01-Al-50026, P20RR015577), the Mary Kirkland Scholarship, the Alliance for Lupus Research and the US Department of Veterans Affairs.

Competing interests None.

Patient consent Obtained.

Ethics approval This study was conducted with the approval of the ethics committee of the Medical Faculty of the University of Erlangen-Nuremberg.

Provenance and peer review Not commissioned; externally peer reviewed.

\section{REFERENCES}

1. Hartl FU. Molecular chaperones in cellular protein folding. Nature 1996;381:571-9.

2. Buchner J. Supervising the fold: functional principles of molecular chaperones. FASEB J 1996;10:10-19. 
3. Zügel U, Kaufmann SH. Role of heat shock proteins in protection from and pathogenesis of infectious diseases. Clin Microbiol Rev 1999;12:19-39.

4. De Nagel DC, Pierce SK. Heat shock proteins implicated in antigen processing and presentation. Semin Immunol 1991;3:65-71.

5. Srivastava $\mathbf{P}$. Roles of heat-shock proteins in innate and adaptive immunity. Nat Rev Immunol 2002;2:185-94.

6. Nardai G, Végh EM, Prohászka Z, et al. Chaperone-related immune dysfunction: an emergent property of distorted chaperone networks. Trends Immunol 2006;27:74-9.

7. Soti C, Pál C, Papp B, et al. Molecular chaperones as regulatory elements of cellular networks. Curr Opin Cell Biol 2005;17:210-15.

8. Ramachandran S, Bell RB. Heat shock protein 70 gene polymorphisms and multiple sclerosis. Tissue Antigens 1995; 46:140-1.

9. Debler J, Schiemann U, Seybold U, et al. Heat-shock protein HSP70-2 genotypes in patients with Crohn's disease: a more severe clinical course with intestinal complications in presence of the Pstl-polymorphism. Eur J Med Res 2003;8:120-4.

10. Clarimón J, Bertranpetit J, Boada M, et al. HSP70-2 (HSPA1B) is associated with noncognitive symptoms in late-onset Alzheimer's disease. J Geriatr Psychiatry Neurol 2003;16:146-50.

11. Ratanachaiyavong $\mathbf{S}$, Demaine $A G$, Campbell RD, et al. Heat shock protein 70 (HSP70) and complement C4 genotypes in patients with hyperthyroid Graves' disease Clin Exp Immunol 1991;84:48-52.

12. Pociot F, Rønningen KS, Nerup J. Polymorphic analysis of the human MHC-linked heat shock protein 70 (HSP70-2) and HSP70-Hom genes in insulin-dependent diabetes mellitus (IDDM). Scand J Immunol 1993;38:491-5.

13. Jarjour W, Reed AM, Gauthier J, et al. The 8.5-kb Pstl allele of the stress protein gene, Hsp70-2: an independent risk factor for systemic lupus erythematosus in African Americans? Hum Immunol 1996;45:59-63.

14. Pablos JL, Carreira PE, Martín-Villa JM, et al. Polymorphism of the heatshock protein gene HSP70-2 in systemic lupus erythematosus. Br J Rheumatol 1995; 34:721-3.

15. Hochberg MC. Updating the American College of Rheumatology revised criteria for the classification of systemic lupus erythematosus. Arthritis Rheum 1997; 40:1725.

16. Tan EMI, Cohen AS, Fries JF, et al. The 1982 revised criteria for the classification of systemic lupus erythematosus. Arthritis Rheum 1982;25:1271-7.

17. Cantor RM, Yuan J, Napier S, et al. Systemic lupus erythematosus genome scan: support for linkage at 1q23, 2q33, 16q12-13, and 17q21-23 and novel evidence at 3p24, 10q23-24, 13q32, and 18q22-23. Arthritis Rheum 2004;50:3203-10.

18. Gaffney PM, Kearns GM, Shark KB, et al. A genome-wide search for susceptibility genes in human systemic lupus erythematosus sib-pair families. Proc Natl Acad Sci USA 1998:95:14875-9.

19. Gray-McGuire C, Moser KL, Gaffney PM, et al. Genome scan of human systemic lupus erythematosus by regression modeling: evidence of linkage and epistasis at 4p16-15.2. Am J Hum Genet 2000;67:1460-9.

20. Nath SK, Namjou B, Hutchings D, et al. Systemic lupus erythematosus (SLE) and chromosome 16: confirmation of linkage to $16 q 12-13$ and evidence for genetic heterogeneity. Eur J Hum Genet 2004;12:668-72.

21. Wakeland EK, Liu K, Graham RR, et al. Delineating the genetic basis of systemic lupus erythematosus. Immunity 2001;15:397-408.

22. Arnett FC. Genetic aspects of human lupus. Clin Immunol Immunopathol 1992;63:4-6.

23. Tan FK, Arnett FC. The genetics of lupus. Curr Opin Rheumatol 1998;10:399-408.
24. Rood MJ, van Krugten MV, Zanelli E, et al. TNF-308A and HLA-DR3 alleles contribute independently to susceptibility to systemic lupus erythematosus. Arthritis Rheum 2000:43:129-34.

25. Fernando MM, Stevens CR, Sabeti PC, et al. Identification of two independent risk factors for lupus within the MHC in United Kingdom families. PLoS Genet 2007;3:e192.

26. Milner CM, Campbell RD. Polymorphic analysis of the three MHC-linked HSP70 genes. Immunogenetics 1992;36:357-62.

27. Favatier $\mathbf{F}$, Bornman L, Hightower LE, et al. Variation in hsp gene expression and Hsp polymorphism: do they contribute to differential disease susceptibility and stress tolerance? Cell Stress Chaperones 1997;2:141-55.

28. Böttcher A, Gaipl US, Fürnrohr BG, et al. Involvement of phosphatidylserine, alphavbeta3, CD14, CD36, and complement C1q in the phagocytosis of primary necrotic lymphocytes by macrophages. Arthritis Rheum 2006:54:927-38.

29. Laemmli UK. Cleavage of structural proteins during the assembly of the head of bacteriophage T4. Nature 1970;227:680-5.

30. Price AL, Patterson NJ, Plenge RM, et al. Principal components analysis corrects for stratification in genome-wide association studies. Nat Genet 2006;38:904-9.

31. Purcell S, Neale B, Todd-Brown K, et al. PLINK: a tool set for wholegenome association and population-based linkage analyses. Am J Hum Genet 2007:81:559-75

32. Barrett JC, Fry B, Maller J, et al. Haploview: analysis and visualization of $L D$ and haplotype maps. Bioinformatics 2005;21:263-5.

33. Milner CM, Campbell RD. Structure and expression of the three MHC-linked HSP7O genes. Immunogenetics 1990:32:242-51.

34. Vargas-Alarcón G, Granados J, Martínez-Laso J, et al. Lack of association between the polymorphism at the heat-shock protein (HSP70-2) gene and systemic lupus erythematosus (SLE) in the Mexican mestizo population. Genes Immun 2000;1:367-70.

35. Singh R, Kølvraa S, Bross P, et al. Heat-shock protein 70 genes and human longevity: a view from Denmark. Ann N Y Acad Sci 2006;1067:301-8.

36. Singh R, Kolvraa S, Rattan SI. Genetics of human longevity with emphasis on the relevance of HSP70 as candidate genes. Front Biosci 2007;12:4504-13.

37. Morimoto RI, Santoro MG. Stress-inducible responses and heat shock proteins: new pharmacologic targets for cytoprotection. Nat Biotechnol 1998;16:833-8.

38. Li Z, Srivastava P. Heat-shock proteins. Curr Protoc Immunol 2004:Appendix 1:Appendix 1T.

39. Macario AJ, Conway de Macario E. Chaperonopathies and chaperonotherapy. FEBS Lett 2007:581:3681-8.

40. Kawaguchi S, Hagiwara A, Suzuki M. Polymorphic analysis of the heat-shock protein 70 gene (HSPA1A) in Ménière's disease. Acta Otolaryngol 2008;128:1173-7.

41. Konings A, Van Laer L, Michel S, et al. Variations in HSP70 genes associated with noise-induced hearing loss in two independent populations. Eur J Hum Genet 2009;17:329-35

42. Oi Y, Niu WO, Zhu TC, et al. Genetic interaction of Hsp70 family genes polymorphisms with high-altitude pulmonary edema among Chinese railway constructors at altitudes exceeding 4,000 meters. Clin Chim Acta 2009;405:17-22.

43. He M, Guo $H$, Yang $X$, et al. Functional SNPs in HSPA1A gene predict risk of coronary heart disease. PLOS ONE 2009;4:e4851.

44. Barcellos LF, May SL, Ramsay PP, et al. High-density SNP screening of the major histocompatibility complex in systemic lupus erythematosus demonstrates strong evidence for independent susceptibility regions. PLoS Genet 2009:5:e1000696. 